\title{
GLOBAL WELL-BEING AND ECONOMIC INEQUALITY
}

Irina GEORGESCU

DICE, Bucharest University of Economic Studies, Bucharest, Romania irina.georgescu@csie.ase.ro

Jani KINNUNEN

Åbo Akademi, Turku, Finland jpkinnunen@gmail.com

Armenia ANDRONICEANU

DAMP, Bucharest University of Economic Studies, Bucharest, Romania armenia.androniceanu@man.ase.ro

Ane-Mari ANDRONICEANU

Bucharest University of Economic Studies, Bucharest, Romania aneama592@gmail.com

\begin{abstract}
The objective of this paper is to find the efficiency of computational methods, namely multinomial logistic regression (MLR) in predicting four classes of human development index (HDI) for 98 world countries for year 2018. In this paper we apply MLR to study the impact of GDP per capita, Net Income Gini index, Wealth Gini index and poverty rate on Human Development Index, for 98 world countries. The MLR model emphasized the nonlinear relationship between economic inequality (measured by GINI indices and poverty rate) and HDI. The logistic regression model achieved 92,9\% accuracy and R-square values over $90 \%$. The results of our research have generated a series of suggestions for the future that can be considered by both international organizations and state governments.
\end{abstract}

Keywords: Human development index, Economic inequality, Logistic regression JEL classification: I31, I32, C38.

DOI: $10.24818 / \mathrm{ie} 2020.05 .05$

\section{Introduction}

Since its introduction in 1990, HDI was aimed to measure human development. It was proved that economic growth and income growth are not the only factors to contribute to well-being [1], [2], [3]. There is a big debate on the supremacy of GDP versus HDI in measuring development. Paper [4] establishes a correlation between GDP and HDI. GDP has been for long a measure of social welfare, measuring a country's output relative to the population. HDI with its three components health, education and income has become the main alternative to GDP [5]. Paper [5] emphasizes how by its three dimensions, HDI assumes the individual participation to the general well-being, e.g. how healthcare access leads to a longer life [6]. The paper is structured as follows. Section 2 describes the relevant basic concepts in literature, followed by section 3 with a theoretical approach to multinomial logistic regression and its application to the dataset. In subsection 3.1, the used data is presented and summarized. The logistic regression approach is applied in subsection 3.2 and the results are interpreted. Section 4 concludes the paper and presents some suggested directions for future research. 


\section{Literature Review}

Globalization causes large-scale changes in technological, economic, political and social fields of social development. These changes have a contradictory impact on the development of national economies and their competitiveness [7]. Economic inequalities and poverty both directly and indirectly influence people's well-being [8], [9]. Economic inequalities are the most obvious, as they show different positions of people in the distribution of income, wealth, goods, including wages [10]. Although the basis of the distribution of income is based on the principles of global economic distribution, the issue of economy, welfare at country and individual level is imperative and can be centered on the policy of equal opportunities for all members of a society [11], [12], [13] If a state government decides to reduce the level of economic inequality [14], [15], it may apply a few sets of tools: (1) redistribution - from those with high incomes to those with low incomes; (2) the grid of opportunities widely available and (3) social responsibility. Redistribution involves taking from the income of those with higher incomes and supplementing the incomes of those with lower incomes [16]. The opportunity grid is a state policy that consisted of offering different opportunities to the vulnerable, in difficulty and helpless. The social responsibility of the organizations [17] is constituted by responsible social initiatives of the economic agents in response to the expectations of the employees, customers, investors and of the company as a whole with regard to the business environment focused on the provision of high quality services, respecting the rights of the employees and solving social problems [18]. The application of these tools by the state governments would allow a reduction of economic inequalities, but at the same time, it should not affect the economic productivity, the labor market and the incentives for investments respectively. The main causes of economic inequalities [19] are: wage inequalities (when some highly skilled workers earn more than those with lower or no qualifications, including gender wage inequalities), the process of globalization, monopolizing certain market segments, technological changes and computerization, fiscal policy, education, political reforms, labor market failures, wealth growth. In this context emphasize the importance to focusing on increasing $R \& D$ expenditures, especially in the higher education sector, as it has a significant influence on improving the global competitiveness development [20]. There are different conceptual approaches to economic inequalities. Some authors [21], [22], [23] believe that economic inequalities are necessary for economic growth. Other authors [24], [25] consider that an analysis of the factors (components) of inequalities is needed to understand why they exist and how their impact on the well-being of the population is reflected.

By using the data for the year 2018 we analyze the correlation between the well-being of the population and the economic inequalities between the selected countries.

\section{Research Methodology}

\subsection{Data Analysis}

In this paper we collected data for 98 world countries available for 2018 from The World Economic Forum's Inclusive Development Index 2018. The dependent variable is HDI and the explanatory variables are GDP per capita (PPP2011), Net Income Gini index, Wealth Gini index and Poverty rate [*]. HDI is a composite index built by United Nations Development Programme (UNPD) used to measure the development of a country. HDI has three components: life expectancy at birth, standard living measured by the natural logarithm of GNI per capita and education (namely, expected years of schooling). Based on 2018 data, HDI is divided into four categories: 0.8-1 (Very High), 0.7-0.799 (High), 0.550-0.699 (Medium), 0.350-0.545 (Low). Of the 98 countries in the analysis, 42 fall into the Very High HDI category, 27 into the High HDI category, 15 into the Medium and 14 into the Low categories. 
The Gini indices help ranking the countries according to their income distribution. When Gini index is close to 1 , it shows perfect inequality. Lower values of GINI index indicate an equal distribution of poverty. It is widely known there is a direct relationship between GDP per capita and the Gini index. GDP per capita is a measure of the welfare of a country; if GDP per capita increases, then the standard of living is better and several people will benefit from the country's economic output. If at the same time the GINI index increases, people will not have increased income. By economic policies, governments will take actions to redistribute wealth.

Figure 1 plots the averages of the used data and shows how in the top Very High HDI class $\left(>75^{\text {th }}\right.$ percentile value) with an average $\mathrm{HDI}=0.885$, the GDP per capita is also the highest, USD 37715 (in 2011 purchasing power parity terms) and consistently over HDI classes decreases to USD 2255 in the bottom Low HDI class with an average HDI=0.488. The top HDI countries are Norway (HDI=0.954, Income gini $=24.9$, wealth gini $=80.5$, and poverty rate of 8.5\%) and Switzerland (0.946, 24.9, 80,5 and 7.8, respectively) and Ireland (0.942, 30,3, 81,3, and $9,1 \%$, respectively). The top-3 countries have GDP per capita of over USD50000 (PPP, 2011). The only other countries reach GDP of USD50000 in our data set. Are Luxembourg (USD 93734, HDI=0.909, income gini $=28,4$, wealth gini $=68,1$, and poverty rate $8,1 \%$ ) and United States (USD55681, 0.92, 37,8, 85,9, and 16,8\%). The United States has the second highest wealth gini $(85,9)$ after only Kazakhstan $(92,6)$. The lowest wealth inequality is seen in Hungary, Slovakia and Iceland $(45,3-46,7)$; the highest income gini is found in Chile $(45,9)$ and Russia $(43,0)$, while the lowest income inequality being found in Iceland, Norway, Denmark and Finland $(24,4-25,6)$ in the group of 42 countries in the Very High HDI category.

Figure 1. Wealth and income inequality, poverty and GDP per capita in HDI classes

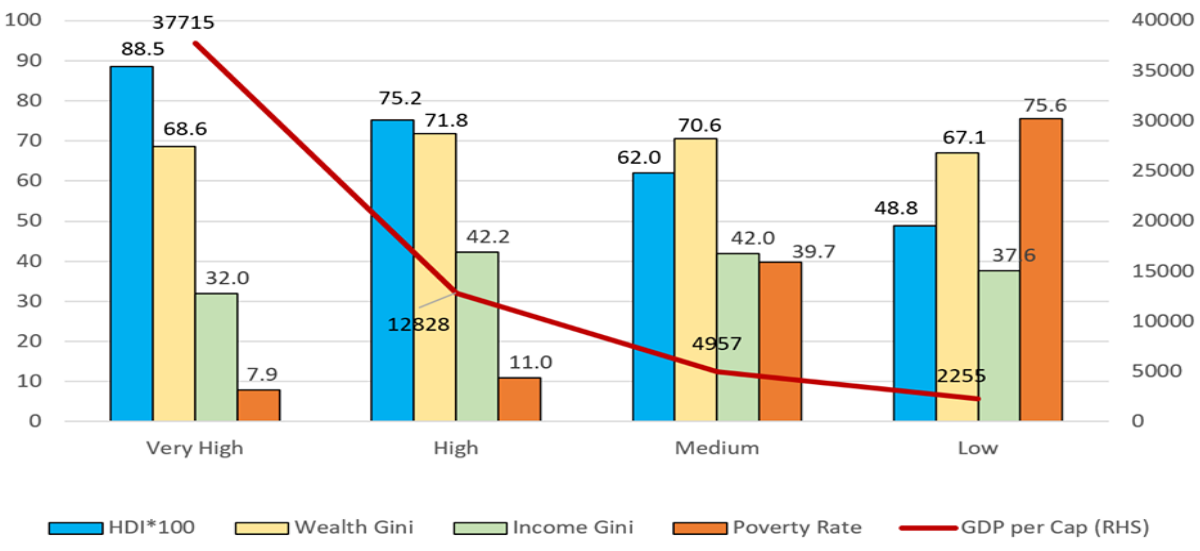

Source: Authors' own research

The High HDI class is topped by countries like Serbia, Iran and Panama, with HDI between 0,795-0.799 and GPD from USD16035 to USD22674, while the category's lowest income inequality is in Ukraine $(26,3)$ and the highest in South Africa $(57,7)$ and lowest wealth gini in Albania $(44,8)$ and highest in Egypt $(0,91)$.

The Medium HDI class ranges from Pakistan $(\mathrm{HDI}=0.56)$ and Zimbabwe $(0,563)$ to Vietnam. The groups GDP ranges from USD2688 of Zimbabwe to Namibia's USD9898. The largest income inequality is in Kyrgystan $(34,1)$ and the smallest in Namibia (55), which also has the lowest wealth inequality (91), Pakistan showing the largest (52.6).

The Low HDI category's HDI ranges from Chad's 0.401 to Rwanda's 0.536 and GDP per capita ranges from Burundi's USD660 to Nigeria's USD5316. The highest income inequality is found in Mauritania $(30,3)$ and the highest wealth inequality in Tansania $(55,2)$. 
Poverty rate shows opposite, but consistent relation to HDI: It is 7,9\% in the top HDI class on average, while $75,6 \%$ in the bottom HDI class; High HDI countries have 11,0\% poverty rate, which increases to $39,7 \%$ on average, when a country falls under the Medium HDI class.

Economic inequality on the aggregate level do not show as consistent behavior as GDP per capita as seen in figure 1: For both, Income gini and Wealth gini, the highest average values are seen in High HDI class (HDI between $50^{\text {th }}$ and $75^{\text {th }}$ percentile), while being only slightly lower in the Medium HDI class (HDI between $25^{\text {th }}$ and $50^{\text {th }}$ percentile), i.e. countries belonging the High and Medium HDI classes are the most economically equal; the greatest wealth inequality is found in the Low HDI countries, while the Very High HDI countries show the highest income inequality. This may reflect the most functional market economy and property rights of the developed countries, where income inequalities work as incentives in labor markets, while the high wealth inequality in the least developed countries may result from less competitive markets with some actors able to accumulate wealth by the expense of other actors. The non-linear relationship between HDI and economic inequalities is handled by multinomial logistic regression, which relaxes the linearity assumption of linear regression models.

\subsection{Multinomial Logistic Regression}

Multinomial Logistic Regression (MLR) is a case of linear regression when the dependent variable is nominal and it has more than two levels. In this section we recall from [26] some well-known formulas on MRL which will be used later in modelling our HDI classification problem. Denote by $\mathrm{Y}$ the categorical variable with $\mathrm{K}$ levels $\{1, \ldots, \mathrm{K}\}$ and the predictors $\left\{X_{1}, \ldots, X_{s}\right\}$.The probability of the level $j$ of $\mathrm{Y}$, for $j=1, \ldots, \mathrm{K}-1$, is $p_{j}(x)=$ $P\left(Y=j \mid X_{1}=x_{1}, \ldots, X_{s}=x_{s}\right)$. The last level $\mathrm{K}$ is usually taken as the reference level, even if it can be a different level, where $\sum_{j=1}^{K} p_{j}(x)=1$. $p_{K}(x)=P\left(Y=K \mid X_{1}=x_{1}, \ldots, X_{s}=x_{s}\right)$. Dividing the relations and applying logarithm, one obtains:

$\ln \frac{p_{j}(x)}{p_{K}(x)}=\beta_{0 j}+\beta_{1 j} x_{1}+\ldots+\beta_{s j} x_{s}$

HDI is the dependent variable and GDP per capita, Net Income Gini, Wealth Gini and Poverty rate are explanatory variables. The objective of MLR is to find the best model between HDI and the independent variables. The reference category of the class variable HDI is High.

Table 1. Model Fitting Information

\begin{tabular}{|l|r|r|r|r|r|r|}
\hline \multirow{2}{*}{ Model } & \multicolumn{3}{|c|}{ Model Fitting Criteria } & \multicolumn{3}{c|}{ Likelihood Ratio Tests } \\
\cline { 2 - 7 } & AIC & BIC & -2 Log Likelihood & Chi-Square & df & Sig. \\
\hline Intercept Only & 257,579 & 265,334 & 251,579 & & & \\
\hline Final & 53,204 & 91,978 & 23,204 & 228,375 & 12 &, 000 \\
\hline
\end{tabular}

Source: Authors' own research

Table 1 compares the null model (only the intercept) and the final model which includes the predictors and the intercept. Akaike Information Criterion (AIC) and Bayesian Information Criterion (BIC) are based on information theory and compare the quality of the null model and the final model. Lower values indicate better models; in our case the final model is preferred since 53,204<257,549 and 91,978<265,334. The -2 Log Likelihood test finds the least possible deviation between the observed and predicted classes of HDI; The lower value 23,204 of the 2 Log Likelihood indicates a better fit for the final model. The likelihood ratio test is an 
alternative to the previous goodness-of-fit tests. The model fit is significant $\chi^{2}(12)=228,375$ , $\mathrm{p}<0,01$, consequently the final model predicts better than the null model.

The goodness-of-fit model by Pearson (Chi-square 20,05) and Deviance (Chi-square=23,20) statistics has the p-values of 1,000>0,05 (lack of significance) indicating a good fit. Similarly, pseudo- $R^{2}$ s have very high values all $>0,90$; the best one is Nagelkerke pseudo $R^{2}$ with the highest value of 0,978 , therefore, they confirm the good fit.

The statistics of table 2 Likelihood Ratio Tests show that both the intercept and the Wealth Gini display p-values less than 0,05 , meaning that they do not have a significant contribution to the full effect.

Table 2. Likelihood Ratio Tests for the Reduced Model

\begin{tabular}{|l|r|r|r|r|r|r|}
\hline \multirow{2}{*}{ Effect } & \multicolumn{3}{|c|}{ Model Fitting Criteria } & \multicolumn{3}{c|}{ Likelihood Ratio Tests } \\
\cline { 2 - 7 } & \multicolumn{1}{|c|}{ AIC } & BIC & -2 Log Likelihood & Chi-Sq. & df & Sig. \\
\hline \multirow{2}{*}{ Intercept } & 52,702 & 83,722 & 28,702 & 5,498 & 3 &, 139 \\
GDPperCapPPP2011 & 124,800 & 155,820 & 100,800 & 77,597 & 3 &, 000 \\
IncomeGini & 61,316 & 92,336 & 37,316 & 14,112 & 3 &, 003 \\
WealthGini & 51,194 & 82,214 & 27,194 & 3,990 & 3 &, 263 \\
PovertyRate & 63,981 & 95,000 & 39,981 & 16,777 & 3 &, 001 \\
\hline
\end{tabular}

Source: Authors' own research

Table 3. Parameter Estimates

\begin{tabular}{|c|c|c|c|c|c|c|c|}
\hline \multicolumn{2}{|l|}{$\mathrm{HDI}^{\mathrm{a}}$} & \multirow{2}{*}{$\begin{array}{l}\text { B } \\
42,981\end{array}$} & \multirow{2}{*}{$\begin{array}{r}\text { Std. Error } \\
47,771\end{array}$} & \multirow{2}{*}{$\begin{array}{l}\text { Wald } \\
, 810\end{array}$} & df & \multirow{2}{*}{$\begin{array}{l}\text { Sig. } \\
, 368\end{array}$} & \multirow[t]{2}{*}{$\operatorname{Exp}(B)$} \\
\hline & Intercept & & & & 1 & & \\
\hline & GDPperCapPPP2011 &,- 004 & ,003 & 1,911 & 1 & ,167 & ,996 \\
\hline \multirow[t]{5}{*}{ Low } & IncomeGini & $-2,304$ & 2,902 & ,630 & 1 & ,427 & 100 \\
\hline & WealthGini & ,460 & ,572 & ,646 & 1 & ,422 & 1,584 \\
\hline & PovertyRate &, 734 & ,799 &, 843 & 1 & ,358 & 2,083 \\
\hline & Intercept & 4,298 & 7,956 & ,292 & 1 &, 589 & \\
\hline & GDPperCapPPP2011 &,- 001 &, 001 & 4,046 & 1 &, 044 & ,999 \\
\hline \multirow[t]{5}{*}{ Medium } & IncomeGini &, 112 & ,296 & , 143 & 1 & ,705 & 1,118 \\
\hline & WealthGini &,- 013 & , 126 & ,010 & 1 & ,920 & ,987 \\
\hline & PovertyRate &, 088 &, 094 &, 883 & 1 & ,347 & 1,092 \\
\hline & Intercept & $-12,094$ & 20,109 & ,362 & 1 &, 548 & \\
\hline & GDPperCapPPP2011 & ,004 & ,006 &, 502 & 1 & ,478 & 1,004 \\
\hline \multirow[t]{3}{*}{ Very High } & IncomeGini & $-2,782$ & 4,217 & , 435 & 1 &, 509 &, 062 \\
\hline & WealthGini &, 513 & ,721 & ,506 & 1 & ,477 & 1,670 \\
\hline & PovertyRate &,- 096 & ,920 & ,011 & 1 & ,917 & 908 \\
\hline
\end{tabular}

a. The reference category is: High.

Source: Authors' own research

The logistic coefficients Beta (B) are interpreted as the change in logit for a unit change in the predictor. Small values of Beta are given by GDP per capita, meaning that this predictor has the least influence on predicting HDI. $\operatorname{Exp}(\mathrm{B})$ (table 3 ) is the odds ratio of each predictor. Predictors with $\operatorname{Exp}(B)$ greater than 1 will increase the logit and predictors with $\operatorname{Exp}(B)$ lower than 1 will decrease it. According to (1), the three MLR equations are: 
$\ln \frac{P(H D I=\text { low })}{P(H D I=\text { high })}=42,981-0,004 G D P-2,304 I G i n i+0,460 W G i n i+0,734 P R$.

From $\operatorname{Exp}(B)$ values for Low HDI category in table 3, one notices that for a one-point increase in GDP per capita, the chances that a country has a low HDI rather than a high HDI decrease with $0,4 \%(1-0,996)$; for a one-point increase in Income Gini, the chances that a country has a low HDI rather than a high HDI decrease with $90 \%(1-0,100)$; for a one-point increase in WealthGini, the chances that a country has a low HDI rather than a high HDI increase with $58,4 \%(1,584-1)$; and for a one-point increase in PovertyRate, the chances that a country has a low HDI rather than a high HDI increase with 108,3\% (2.083-1).

$\ln \frac{P(H D I=\text { medium })}{P(H D I=\text { high })}=4,298-0,001 G D P+0,112$ IGini $-0,013 W G i n i+0,088 P R$.

$\operatorname{Exp}(B)$ values for Medium HDI category in table 3 show that: for a one-point increase in GDP per capita, the chances that a country has a medium HDI rather than a high HDI decrease with $0,1 \%$; for a one-point increase in Income Gini, the chances that a country has a medium HDI rather than a high HDI increase with $11,8 \%$; for a one-point increase in WealthGini, the chances that a country has a medium HDI rather than a high HDI decrease with 1,3\%; and for a onepoint increase in PovertyRate, the chances that a country has a medium HDI rather than a high HDI increase with $9,2 \%$.

$\ln \frac{P(H D I=\text { veryhigh })}{P(H D I=\text { high })}=-12,094-0,004 G D P-2,782$ IGini $-0,513$ WGini $-0,096 P R$.

$\operatorname{Exp}(B)$ values for Very High HDI category in table 3 show that: for a one-point increase in GDP per capita, the chances that a country has a very high HDI rather than a high HDI increase with $0,4 \%$; for a one-point increase in Income Gini, the chances that a country has a very high HDI rather than a high HDI decrease with 93,8\%; for a one-point increase in WealthGini, the chances that a country has a very high HDI rather than a high HDI increase with 67\%; and for a one-point increase in PovertyRate, the chances that a country has a very high HDI rather than a high HDI decrease with $9,2 \%$.

Table 4 shows the performance of the MLR classifier. The overall accuracy is $92,9 \%$, which means that the full model (with coefficients and intercept) correctly classifies the 98 countries.

Table 4. Classification

\begin{tabular}{|l|r|r|r|r|r|}
\hline \multirow{2}{*}{ Observed } & \multicolumn{5}{|c|}{ Predicted } \\
\cline { 2 - 6 } & High & Low & Medium & Very High & Percent Correct \\
\hline High & 25 & 0 & 2 & 0 & $92,6 \%$ \\
Low & 0 & 12 & 2 & 0 & $85,7 \%$ \\
Medium & 1 & 1 & 13 & 0 & $86,7 \%$ \\
Very High & 1 & 0 & 0 & 41 & $97,6 \%$ \\
Overall Percentage & $27,6 \%$ & $13,3 \%$ & $17,3 \%$ & $41,8 \%$ & $92,9 \%$ \\
\hline
\end{tabular}

Source: Authors' own research

\section{Conclusions}

The predictive power of economic inequalities (measured by the wealth and income gini) with respect to the United Nations' human development index, HDI, has been studied together with 
the gross domestic product (GDP per capita) in 98 world countries. The logistic regression model achieved $92,9 \%$ accuracy and $>90 \%$ R-square values. Thus, the MLR captured the nonlinear relationship of inequalities and HDI. In this study, only cross data was considered for year 2018. The statistical significance levels are expected to be higher with time-series data. Further, more elaborate models, e.g. based on neural networks may even further enhance the predictive performance of inequalities on well-being measures. Income inequalities seem to work as incentives in the relatively functioning market economies and the related established institutions of the most developed countries [27], [28], while rent seeking and negotiation power in the lowest HDI countries may have resulted in the highest wealth inequalities depending on political and other institutional structures [29]. The decile-wise wealth and income inequality data may prove useful with other mega-trends, such as digitalization [30], which generate well-being with unknown inequality effects.

\section{References}

[1] G. Gallardo, "The human development index as an effort to measure well-being in Honduras", The 3rd OECD World Forum on Statistics, Knowledge and Policy, Busan, Korea, 2009.

[2] I. Georgescu and J. Kinnunen, "Well-being and economic freedoms in OECD", Proceedings of the $12^{\text {th }}$ LUMEN International Scientific Conference Rethinking Social Action: Core Values in Practice, Iasi, Romania, pp. 108-125, 2019.

[3] A. M. Andrei and I. Georgescu, "Socio-economic inequality and economic growth: Measurements for Central and Eastern Europe", Chinese Business Review, vol. 17, no.11, pp. 547-570, 2018.

[4] J. Hudáková, "Relationship between Gross Domestic Product and Human Development Index", Research Report, 2018.

[5] A. D. Sagar and A. Najam, "The Human Development Index: A Critical Review", Ecological Indicators, vol. 25, pp. 249-264, 1998.

[6] J. Bilbao-Ubillos, "The limits of Human Development Index: The Complementary Role of Economic and Social Cohesion, Development Strategies and Sustainability", Sustainable Development, vol. 21, pp. 400-412, 2011.

[7] H. Fyliuk, I. Honchar and V. Kolosha. "The interrelation between economic growth and national economic competitiveness: the case of Ukraine", Journal of Competitiveness, vol. 11, no.3, pp. 53-69, 2019. Available: https://doi.org/10.7441/joc.2019.03.04

[8] Y. Bilan, H. Mishchuk, N. Samoliuk and H. Yurchyk, "Impact of income distribution on social and economic well-being of the state, Sustainability, vol. 12, no.1, p. 429, 2020.

[9] H. Mishchuk, N. Samoliuk, Y. Bilan and D. Streimikiene, „Income inequality and its consequences within the framework of social justice", Problemy Ekorozwoju, vol. 13, no.2, pp. 131-138, 2018.

[10] S. Stjepanović; D. Tomić and M. Škare, "A new approach to measuring green GDP: a cross-country analysis", Entrepreneurship and Sustainability Issues, vol.4, no.4, pp. 574-590, 2017. Available: http://dx.doi.org/10.9770/jesi.2017.4.4(13)]

[11] J. Belas, L.Belas, M. Cepel and Z. Rozsa, "The impact of the public sector on the quality of the business environment in the SME segment", Administratie si Management Public, vol. 32, pp. 1831, 2019, DOI: $10.24818 / \mathrm{amp} / 2019.32-02$

[12] N. Meyer and D.F. Meyer, "The relationship between the creation of an enabling environment and economic development: A comparative analysis of management at local government sphere", Polish Journal of Management Studies, vol. 14, no. 2, pp. 150-160, 2016.

[13] M. Haseeb, S Kot, H.I. Hussain and K. Jermsittiparsert, "Impact of economic growth, environmental pollution, and energy consumption on health expenditure and R\&D expenditure of ASEAN countries", Energies, vol. 12, no.19, art. no. 3598, 2019.

[14] R. Prakash and P. Garg, "Comparative assessment of HDI with Composite Development Index (CDI)", Insights into Regional Development, vol. 1, no.1, pp. 58-76, 2019. Available: https://doi.org/10.9770/ird.2019.1.1(5) 
[15] J. Baltgailis, "The issues of increasing the effectiveness of teaching comparative economics", Insights into Regional Development, vol. 1, no.3, pp. 190-199, 2019. Available: https://doi.org/10.9770/ird.2019.1.3(1)

[16] A. Androniceanu and M. Tvaronavičiene, "Developing a holistic system for social assistance services based on effective and sustainable partnerships", Administratie si Management Public, vol. 33, pp. 103-118, 2019, DOI: 10.24818/amp/2019.33-06.

[17] A. Androniceanu. "Social responsibility, an essential strategic option for a sustainable development in the field of bio-economy", Amfiteatru Economic, vol.21, no.52, pp. 347-364, 2019.

[18] G. Çera, M. Meço, E. Çera and S. Maloku, "The effect of institutional constraints and business network on trust in government: an institutional perspective", Administratie si Management Public, 33, 2019, pp. 6-19, DOI: 10.24818/amp/2019.33-01.

[19] L. Smékalová. "Evaluating the cohesion policy: targeting of disadvantaged municipalities", Administratie si Management Public, vol. 31, pp. 143-154, 2018, DOI: 10.24818 /amp/2018.31-10.

[20] D. Kiselakova, B. Sofrankova, V. Cabinova, E. Onuferova and J. Soltesova, "The impact of R\&D expenditure on the development of global competitiveness within the CEE EU Countries", Journal of Competitiveness, 10(3), pp. 34-50, 2018. Available: https://doi.org/10.7441/joc.2018. 03.03.

[21] E. Dul'ová Spišáková, L. Mura, B. Gontkovičová and Z. Hajduová, "R\&D in the context of Europe 2020 in selected countries", Economic Computation and Economic Cybernetics Studies and Research, vol.51, no.4, pp. 243 - 261, 2017.

[22] A. G. Raišienè, S. Bilan, V, Smalskys and J. Gečienė, "Emerging changes in attitudes to interinstitutional collaboration: the case of organizations providing social services in communities", Administratie si Management Public, vol. 33, pp. 34-56, 2019, DOI: 10.24818/amp/2019.33-03.

[23] D. Jašková. "Assessment of social development in Slovakia in the context of human resources", Central European Journal of Labour Law and Personnel Management, 2 (2), pp. 21-32, 2019, doi: 10.33382/cejllpm.2019.03.02

[24] H. Z. Ivancsóné and E. Printz-Markó, "Territorial differences between countries with regard to the wellness lifestyle of their youth", Forum Scientiae Oeconomia, vol. 6, no.3, pp. 101-117, 2018.

[25] A. Ključnikov and M. Sobeková Majková, "Impact of gender in the perception of administrative burdens among young entrepreneurs - evidence from Slovakia", Journal of Competitiveness, vol. 8, no.2, pp. 17-30, 2016, DOI: 10.7441/joc.2016.02.02

[26] C.C. Aggarwal,"Data Classification Algorithms and Applications”, Chapman and Hall/CRC, 2014.

[27] J. Kinnunen, I. Georgescu and L. Tamminen, "Do economic freedoms create national wealth? Clustering and principal component analyses of freedom variables and GDP", Proc. The Real Options Workshop, Lappeenranta, Finland, October 3-4, 2017.

[28] J. Kinnunen, "Islamic Countries Clustered and Analysed by Economic and Political Freedoms and GDP", Proceedings of the 6th International Islam \& Liberty Conference: Building an Islamic Case for Open Markets, pp. 19, 2018.

[29] J. Kinnunen, A. Androniceanu and I. Georgescu, "The role of economic and political features in classification of countries-in-transition by Human Development Index", Informatica Economica, vol. 23, no.4, pp. 26-40, 2019.

[30] I. Georgescu and J. Kinnunen, "The digital effectiveness on economic inequality: a computational approach", Proceedings of the International Conference on Business Excellence (ICBE 2020), Bucharest, Romania (forthcoming).

[*] https://www.gfmag.com/global-data/economic-data/wealth-distribution-income-inequality 